\title{
The slaughter of Sahelian wildlife by Arab royalty
}

\author{
John E. Newby
}

Once the Sahel supported healthy populations of wildlife. Today only remnant populations exist, survivors of the ravages of drought, desertification, excessive hunting and competition for pasture. In the past few years the problems for these animals and for the people trying to conserve them have been exacerbated by a new wave of hunters. Arab princes and their retinues, having exterminated most of the prey species in their native land, are invading the Sahelian countries in search of new hunting grounds. The author, who has worked for 20 years in the Sahel, here describes what is happening in Niger and Mali and urges that steps be taken to stop the slaughter.

Once the home of four species of gazelle (scientific names are given in Table 1), addax, scimitar-horned oryx, cheetah, ostrich and bustards, the sub-desert rangelands of the Sahel are now virtually empty. Little has escaped the ravages of the past decades drought, desertification, over-hunting, competition for pasture. Now the Sahelian nations are seeing the remains of their once abundant fauna squandered to satisfy the whims of a privileged and irresponsible minority.

The people concerned are certain members of some Arab royal families and their followers. In Mali one prince has visited five or six times since 1982. I recently visited one of his camps after his departure and found bustard feathers scattered over an area of several hundred square metres. There was a pit into which bustard remains had been thrown, and a cursory investigation revealed a number of bustard heads and the skin of a young dorcas gazelle. I identified the skulls of both the

Table 1. Scientific names of species mentioned in the text

\begin{tabular}{ll}
\hline Ostrich & Struthio camelus \\
Nubian bustard & Neotis nuba \\
Sudan bustard & Otis arabs \\
Common jackal & Canis aureus \\
Sand fox & Vulpes ruppelli \\
Dorcas gazelle & Gazella dorcas \\
Slender-horned gazelle & Gazella leptoceros \\
Red-fronted gazelle & Gazella rufifrons \\
Dama gazelle & Gazella dama \\
Scimitar-horned oryx & Oryx dammah \\
Addax & Addax nasomaculatus \\
\hline
\end{tabular}

Nubian and the Sudan bustard; the former is listed as threatened in the ICBP/IUCN Bird Red Data Book, and all bustards were recently listed on the Appendices of the Convention on International Trade in Endangered Species of Wild Fauna and Flora.

The story is always the same: hundreds (some say thousands) of bustards are slaughtered as well as gazelles, hares and sandgrouse. Officially in Mali to hunt with falcons, the Prince and his retinue cannot be described as traditional sportsmen. Their caravan resembles a mini-army on manoeuvres, with fourwheeled drive vehicles, water tankers, generator trucks and weapons including automatic rifles. Deep freezers keep the 'bag' fresh until it is either eaten or flown back to Saudi Arabia. It is small compensation to learn from local nomads that not all wildlife seen is slaughtered. Some animals are captured live, probably for private and frequently badly kept collections. Such activities are putting an enormous strain on the increasingly endangered populations of gazelle and bustard.

The situation in Mali is nothing new. With bustard populations wiped out, wealthy Arabs are being forced further afield in search of quarry. Yesterday it was the Sudan, Algeria and Morocco; today Mali and Niger; tomorrow, who knows?

If the wildlife of the Sahel is to escape extermination this kind of hunting must stop. It is essential that Saudi Arabia exerts pressure on the errant members of their royal family, but the official view there seems to be that the 


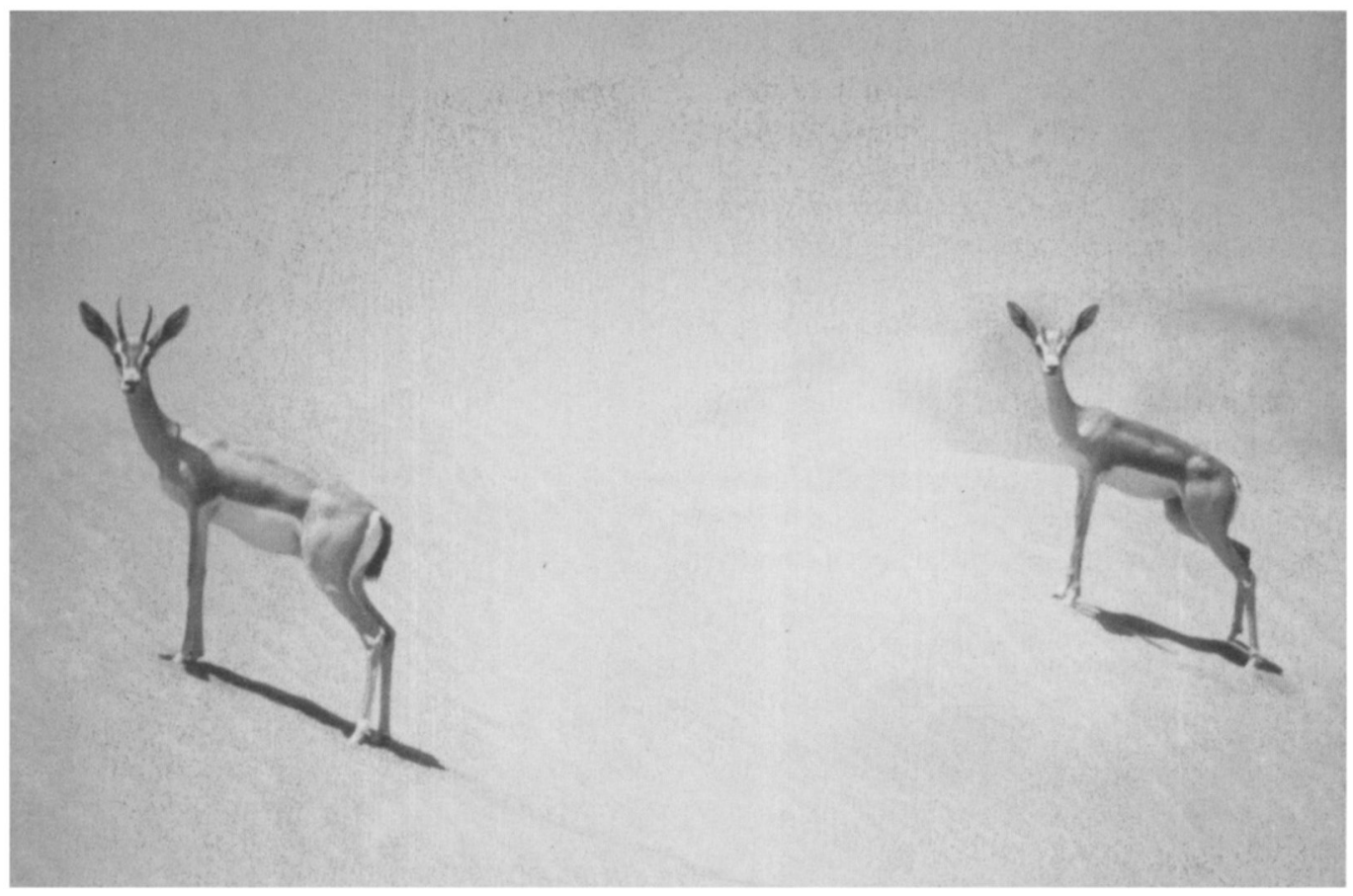

Dorcas gazelle: becoming increasingly endangered as a result of hunting (John E. Newby).

solution of the problem rests with the Sahelian nations themselves; they should refuse to allow the hunts. This is not only an irresponsible attitude, but also an unrealistic one. Unaided, the hard-pressed Sahelian nations would find it difficult to risk the wrath of their politically and financially dominant Islamic brethren. The Arab nations must assume at least some of the burden in solving this problem, especially as they strive themselves to educate their own peoples about wildlife conservation and its importance to the future of their respective countries.

The Sahelian nations will also need to play a role if the wildlife is to survive. The obvious solution would be to find ways in which the wildlife could provide much needed income. There are thousands of square kilometres of arid land that once supported healthy wildlife populations. Needing little or no free water, capable of migrating long distances in search of grazing and feeding on the relatively few plants able to survive the rigours of the desert climate, wildlife exploited vast tracts of marginal land very successfully.

While it is tempting to consider exploiting this resource for food for local use, it is probably not an economically viable proposition. Even assuming that a partial rehabilitation of certain wildlife populations is possible, Sahelian ungulates are nowhere as densely populated as those frequenting savannah. Under extreme conditions, say during a famine, the culling of gazelles, for example, might be possible, but not very practical.

Sport hunting would seem to be a better proposal. Assuming that it is properly controlled and well thought out, it would be sustainable and make economic sense. Falconers and other sport hunters could go a long way towards making wildlife generate a sustainable income for impoverished local people, at the same time ensuring the continuity of their sport.

Wildlife-orientated tourism can also generate substantial income, but the Sahel, unlike the Serengeti, is unlikely to attract the average tourist on its wildlife merits alone. As part of a broader spectacle, the wildlife element is 
nonetheless an important asset. In Niger's newly-created Aïr and Ténéré National Nature Reserve, some 2000-3000 tourists clamour annually for a sight of the reserve's increasingly unique wildlife resources.

Lastly, wildlife has always played a major role in man's cultural and religious traditions. Sahelian development plans frequently overemphasize the technical and financial aspects, overlooking the largely unquantifiable socio-cultural considerations. With his land ravaged by drought and desertification, and his existence reduced to the success or failure of an alien and largely incomprehensible development project, the average Sahelian is rapidly

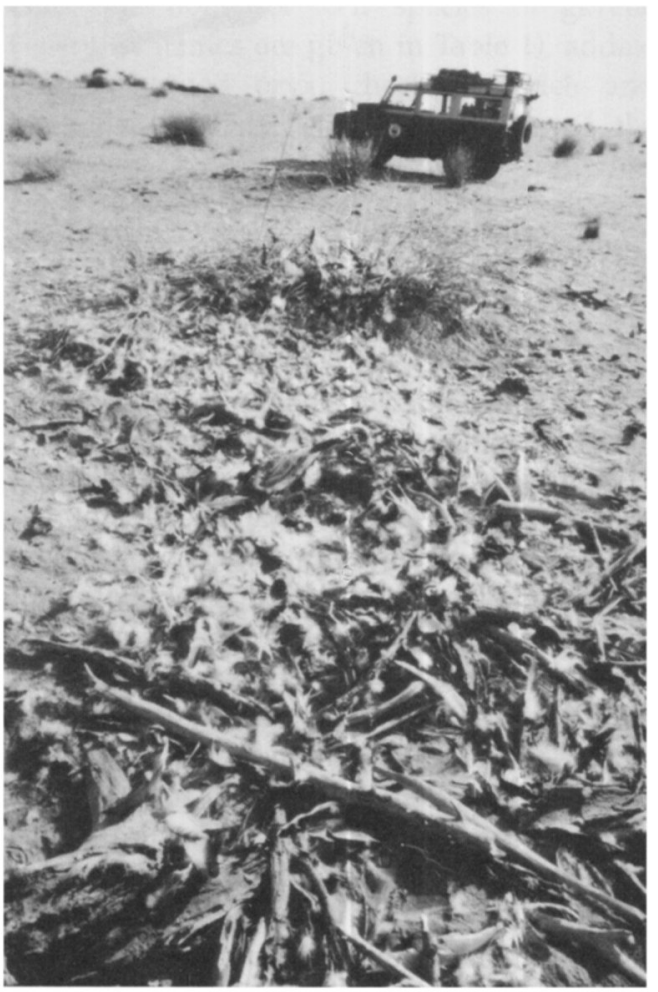

Midden with feathers and remains of bustards killed by Arabs, Mali (WWF/John E. Newby).

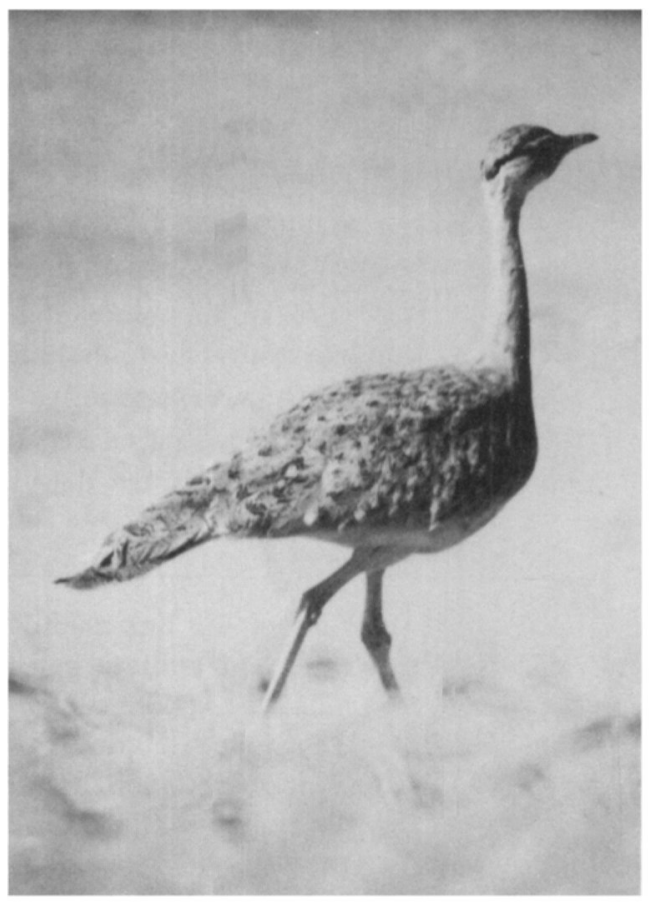

Nubian bustard, a threatened species which is being slaughtered in large numbers by hunters from Saudi Arabia (John E. Newby).

losing all physical and spiritual contact with his homeland and with the things he understands, respects and relates to. The maintenance of this relationship is, I am sure, a powerful factor in coping with and reversing the problems that face the Sahel. The majority of Sahelians genuinely regret the disappearance of their wildlife. These same people would undoubtedly support rehabilitation projects if their governments would put a halt to the double standard of preventing the poor from hunting for food while allowing the rich and powerful to commit their butchery.

John Newby, IUCN/WWF Representative, BP 10933, Niamey, Niger. 